\title{
Progressive noninfectious anterior vertebral fusion
}

\author{
Paulo Cesar Rocha Oliveira • \\ Denise de Deus Leopoldino
}

Received: 5 August 2010 /Revised: 31 August 2010 / Accepted: 7 September 2010/Published online: 5 October 2010

(C) Springer-Verlag 2010

A 9-year-old girl with back pain showed progressive spinal mobility restriction since age one, without a history of spondylodiscitis or neurological deficits. Laboratory tests were normal. Radiographs revealed lumbar lordosis rectification, anterior fusion between end plates from L2-L3 to L4-L5 levels, with prominent bone bridge in the latter, and anterior intervertebral narrowing at T11-T12 and L1-L2 (Fig. 1).

MRI showed slight hypersignal on T1- and T2-W images in the anterior portion of the multiple end plates (Fig. 1). There were no other spinal or clinical abnormalities. The clinicoradiological diagnosis was progressive, noninfectious anterior vertebral fusion, a rare disorder of early childhood with unknown etiology. It can be asymptomatic or associated with moderate pain, rigidity, thoracolumbar kyphosis and, rarely, neurological impairment [1]. Radiologically, it may start with anterior defects in the end plates, associated with local intervertebral narrowing accompanied by erosion and irregularity of the corresponding end plates and then fusion, which typically spares the posterior disc space, except in the late stages $[1,2]$. Treatment generally consists of spinal bracing [2].
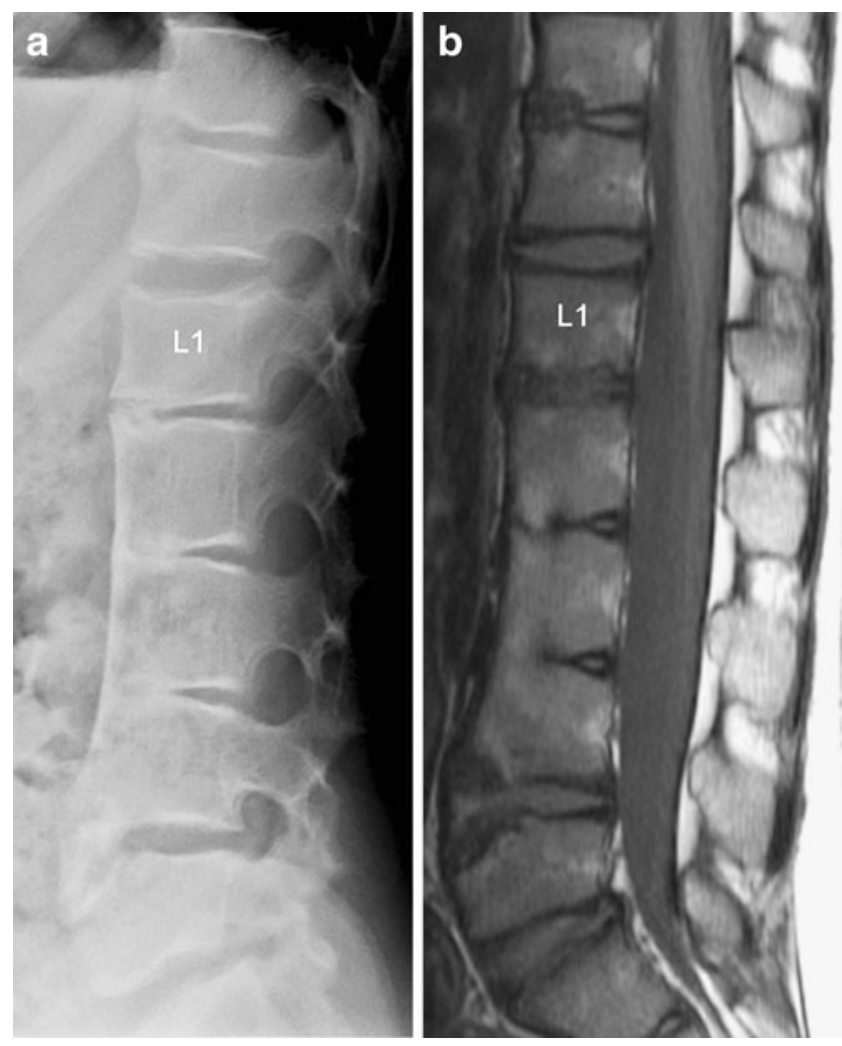

Fig. 1 Lumbar spine. a Radiograph, lateral view. b MRI, sagittal T1-W

\section{References}

1. Hughes RJ, Saifuddin A (2006) Progressive non-infectious anterior vertebral fusion (Copenhagen syndrome) in three children: features on radiographs and MR imaging. Skeletal Radiol 35:397-401

2. Decarie JC, Babyn PS (1993) Progressive noninfectious anterior vertebral fusion: MRI findings and association with a lipoma of the filum terminale in a 5-year-old girl. Pediatr Radiol 23:12-14 